\title{
High School Environments, STEM Orientations, and the Gender Gap in Science and Engineering Degrees*
}

\author{
Joscha Legewie and Thomas A. DiPrete \\ Columbia University and University of Wisconsin - Madison Madison
}

July 21, 2011

\begin{abstract}
This study examines two important and related dimensions of the persisting gender gap in science, technology, engineering, and mathematics (STEM) bachelor degrees: First, the life-course timing of a stable gender gap in STEM orientation, and second, variations in the gender gap across high schools. We build on existing psychological and sociological gender theories to develop a theoretical argument about the development of STEM orientations during adolescence and the potential influence of the local high school environment on the formation of STEM orientations by females and males. Using the National Education Longitudinal Study (NELS), we then decompose the gender gap in STEM bachelor degrees and show that the solidification of the gender gap in STEM orientations is largely a process that occurs during the high school years. Far from being a fixed attribute of adolescent development, however, we find that the size of the gender gap in STEM orientation is quite sensitive to local high school influences; going to school at a high school that is supportive of a positive orientation by females towards math and science can reduce the gender gap in STEM bachelor degrees by $25 \%$ or more.
\end{abstract}

\footnotetext{
${ }^{*}$ This project was supported by Award Number R01EB010584 from the National Institute Of Biomedical Imaging And Bioengineering. The content is solely the responsibility of the authors and does not necessarily represent the official views of the National Institute Of Biomedical Imaging And Bioengineering or the National Institutes of Health.
} 


\section{Introduction}

When then-Harvard President Lawrence Summers pointed at innate differences between men and women as a possible explanation for women's under-representation in high level science positions, he sparked an intense public controversy that mirrors a continuing debate in the scientific community. Despite the striking reversal of the gender gap in educational attainment (Buchmann and DiPrete 2006) and the near gender parity in math performance (Hyde et al. 2008), women still pursue science, technology, engineering, and mathematics (STEM) degrees at much lower rates than their male peers do. Figure 1 illustrates these trends. It shows, on the one hand, how women have made impressive gains in college attainment compared to men and now clearly outnumber men among college graduates in recent decades. On the other hand, women continue to lag behind in terms of bachelor degrees awarded in the 'quantitative' sciences (illustrated in the graph for different STEM sub-fields). ${ }^{1}$ This persistent pattern of gender inequality in college science majors and the implications for later career choices and labor market earnings has been a major concern for scientist and policy-makers alike. Such differences are not only relevant for the representation of women in high income and prestigious jobs and as such for gender equality in general but also for the supply of qualified labor in science oriented jobs, which is often regarded as a linchpin for the future of the US economy in an increasingly competitive global environment.

In this paper, we explore two important and related dimensions of the persisting gender gap in STEM degrees. The first dimension is the timing of the emergence of a gender gap in orientation towards STEM fields. Our analysis of the middle-school through college phase of the educational life course reveals that the high school years play a major role in shaping gendered orientations toward science and engineering. The second dimension concerns the impact of the high school environment on the development of these orientations during the decisive high school years. In particular, we use multilevel models to document how the gender gap in STEM orientation in twelfth grade varies across high schools, and we estimate the causal effect of the high school curriculum on the gender gap in STEM orientation. Far from being a fixed attribute of adolescent development, we find that the size of the gender gap in STEM orientation is quite sensitive to local high school influences; going to school in a high school that is supportive of a positive orientation by females towards math and science can reduce the gender gap in STEM bachelor degrees by $25 \%$ or more. Together these two dimensions of timing and local environmental influence extend existing theories and open concrete avenues for policy intervention.

\footnotetext{
${ }^{1}$ Exceptions to this trend are the biological, biomedical and life sciences, in which women today outnumber men.
} 
Figure 1: Gender Gap in Bachelor Degrees Awarded by Field of Study, 1969-2007

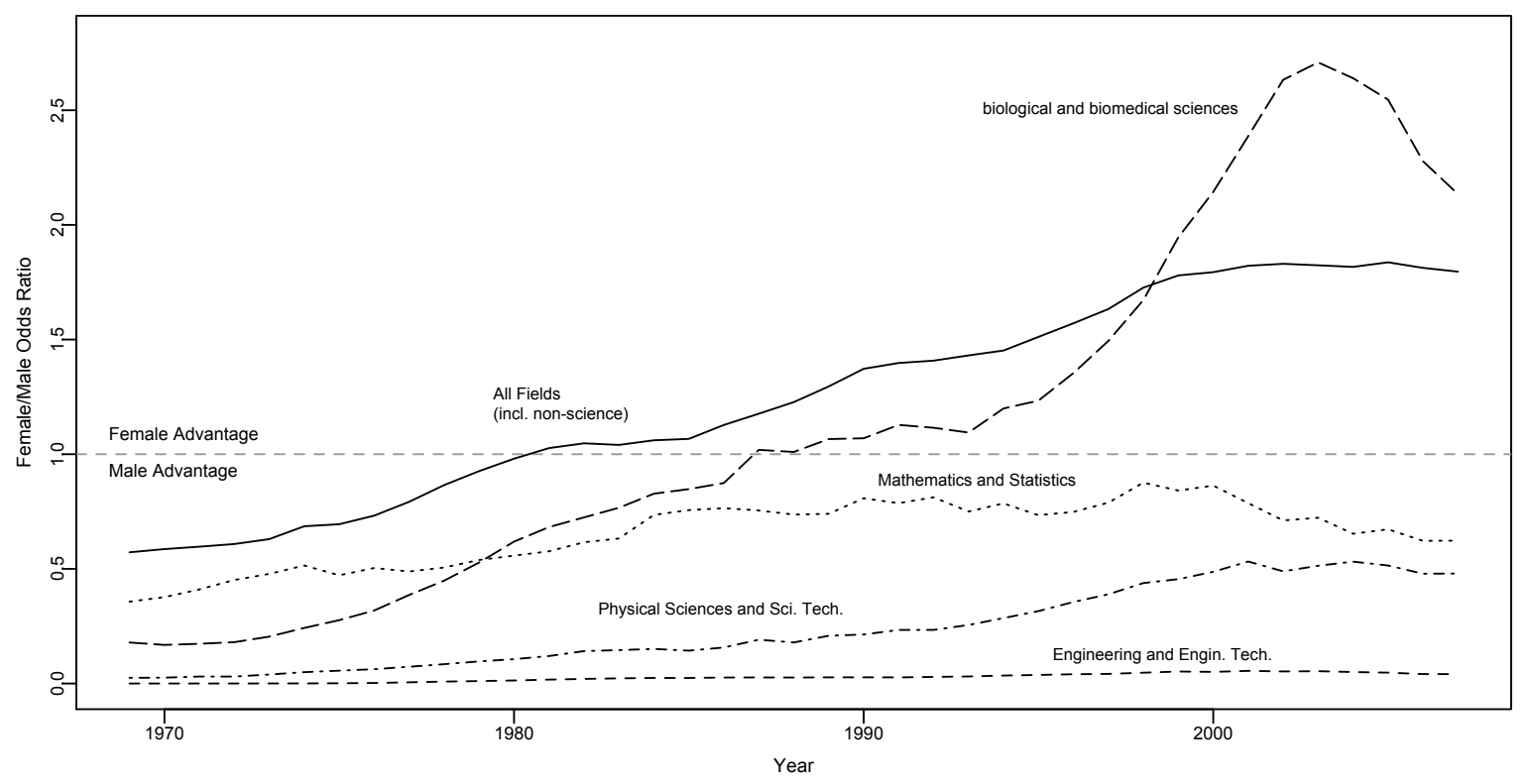

Source: Digest of Educational Statistics 2009, Table 268, 299, 303, 305, 312 and 313

We begin by developing a theoretical argument about the development of STEM orientations during adolescence, and the potential influence of the local environment on the formation of STEM orientations by females and males. While acknowledging the importance of the global environment, we argue that local environments centrally affect the strength and salience of gender stereotypes about math and science. Their influence operates mainly through two important processes. First, peers, parents and teachers - all important actors in the local environment - support and encourage certain career paths for boys and girls while disparaging others. Second, the influence of gender stereotypes about STEM occupations depends on the level of exposure to STEM academic courses and to information about STEM fields and STEM occupations. Both arguments imply that the size of the gender gap in STEM bachelor degrees is shaped to a considerable extent by the character of the high school environment. Variations in this environment will therefore affect the size of the gender gap in STEM orientations.

We then turn to an empirical examination of the timing and the local variation across high schools. First, we decompose the gender gap in STEM bachelor degrees into various pathways to examine the emergence and solidification of gender differences in the orientation towards science and engineering in the adolescent life course. In particular, we use the National Education Longitudinal Study (NELS) to follow the 1988 cohort of eighth grade students through adolescence and young adulthood, and observe how orientations towards STEM fields emerge and change from eighth grade through college. 
We find that the substantial gender gap in eighth grade orientation is relatively inconsequential for the persisting gender gap in STEM degrees at the completion of college. Instead, the high school years play a major role in shaping gendered orientations towards science and engineering. Second, we examine the role of the high school for this decisive period. In particular, we use multilevel models to document how the gender gap in STEM orientation at the end of high school varies across high schools, and we estimate the causal effect of high school curriculum on the gender gap in STEM orientation. The results show substantial variation in the gender gap in STEM orientation across schools, which supports our argument that the local environment plays a major role in shaping these orientations among boys and girls. The significant effect of high school curriculum on the gender gap in STEM orientation provides the beginning of an understanding about the source of the high school effect. Our results imply that the gender gap could be considerably reduced if high school environments were reshaped to model those high schools that are most supportive of female interest and competency in science and mathematics.

\section{Explanations for the Persisting Gender Gap in STEM Degrees}

The most prominent explanations of the persisting gender gap in STEM degrees revolve around two issues. First, the debate about gender differences in math ability continues to the present day even though the gender gap in math performance has largely closed. The second area focuses on women's lack of interest in STEM fields and is related to multiple factors such as job-related values, occupational preferences, and work-family balance.

Recent research on differences in math ability has shown that the gender gap in math performance (Hyde et al. 2008) and course taking (Xie and Shauman 2005, Cha. 2) has largely closed; female performance on math tests is very similar to that of males. Girls take at least as many math classes in high school as do boys, and the classes are at a similar level of rigor (Lee et al. 2007). These facts notwithstanding, gender differences in math ability continue to play an important role in the debate about the persisting gender gap in STEM degrees. This debate largely revolves around findings that males excel at spatial orientation and visualization (Kimura 2002, 142f), and are more likely to fall on the extremes of the performance distribution in standardized mathematics tests (Ellison and Swanson 2010; Lohman and Lakin 2009; Hedges and Nowell 1995). The male advantage in the right tail of mathematics tests may have implications for gender inequality in STEM degrees, though a connection between the two facts remains controversial (Xie and Shauman 2005, 89ff; Weinberger 2005). Meanwhile, Ceci et al. (2009) casts persuasive doubt on the power of the spatial ability theory 
to account for observed gender differences in STEM degrees.

The second area of active debate about the persisting gender gap in STEM degrees focuses on gender differences in career preferences. Surveys consistently show that women are less interested in STEM fields from early adolescence (e.g. Lapan et al. 2000) both in the general population and in the subpopulation of high performing students (Lubinski and Benbow 1992). A number of studies suggest that females are more interested in jobs involving people and social interactions, and emphasize intrinsic, altruistic, and social rewards associated with an occupation. Males, in contrast, are more interested in jobs involving physical objects and abstract concepts, and place a higher value on extrinsic rewards such as money, prestige, and power (Eccles 2007; Beutel and Mooney Marini 1995; Johnson 2001; Davies and Guppy 1996; Konrad et al. 2000). Thus, gender differences in attitudes and values might explain, in part, why adolescents' expectations about college major and occupation remain quite gender typed (Lueptow et al. 2001; Wilson and Boldizar 1990).

Gender differences in values and attitudes are associated with the division of labor in the family. Since the construction of masculinity commonly places work at the center of adult life, boys tend not to experience conflict between their work and family roles (Arnold 1995; Eccles and Hoffman 1984). But because the perception of femininity emphasizes the importance of family, conflict between work and family is a prominent feature of women's lives (Duxbury and Higgins 1991; Williams 2000). Young women anticipate this career-family conflict long before they experience it firsthand (Shauman 2008). Even career-oriented women may take a contingency approach to planning their future by choosing career paths that they perceive to be compatible with future family roles (Almquist et al. 1980; Angrist and Almquist 1993; Felmlee 1993; Okamoto and England 1999; Gerson 1985; Seymour and Hewitt 1997).

Males and females also appear to differ in their self-evaluations about math and science aptitude. According to the Expectancy-Value model (Eccles 1994; Eccles 2007) an individual's expectations for success, and the value that he or she attaches to the task are directly related to individuals' educational and occupational choices. Along with gender differences in job values and expected adult roles, gender differences in perceived skills appear to attenuate women's interest in STEM fields (Correll 2001; Pajares 2005).

\section{The Nature and Origin of Gender Differences}

The existence of small differences between the genders in mathematics ability and larger differences in values, attitudes, and self-evaluations beg the questions of how these differences arise and how mutable 
they may be. Biological theories suggest that the differences in performance and preferences are at least partly the result of innate genetic, hormonal, and brain structure differences between males and females that largely emerged through evolutionary processes driven by the different reproductive roles of men and women (Lippa 2005; Halpern 2000, Cha. 4). Cognitive psychological theories similarly see the formation of basic gender identity as preceding behavior and emerging through cognitive processes (Martin et al. 2002, 911). Recent investigations, however (Ceci et al. 2009; Penner 2008; Guiso et al. 2008; Andreescu et al. 2008), downplay the relative importance of biological factors and point at substantial cross-national variations in the size of the gender gap as evidence for the importance of cultural factors in the formation of gendered identities and behaviors.

Some psychological theories - in particular Bussey and Bandura's (1999) "social cognitive theory" of gender development - attempt to integrate psychological and sociological approaches to gender roles in order to account for the apparent environmental influences on gender development. More broadly, sociological and social-psychological gender theories generally view gender as socially constructed i.e., as a product of gender stereotypes about femininity and masculinity. Gender stereotypes set up expectations about appropriate preferences and behavior, and thereby influence how boys and girls perceive themselves, how they perform their gender to construct their own identity, and how they perceive others perceiving and reacting to them as boys and girls. ${ }^{2}$ Status expectation theory further argues that gender stereotypes typically include status beliefs that attach greater competence in valued skills to the advantaged status (Ridgeway 2001).

Gender stereotypes are relevant for the persisting gender gap in STEM degrees because they encompass beliefs about social roles connected to housework and child-rearing, and about skills such as math and science ability as well as appropriate occupations (Charles and Bradley 2002). Based on status expectation theory, Correll (2001) also argues for a gender bias in the self-assessment of career relevant tasks such as math skills and shows how bias affects career relevant decisions. Status beliefs, like other aspects of STEM-related gender stereotypes arise from the socio-cultural environment (Correll 2004; Hill et al. 2010). Thus, heterogeneity in behavior can arise not simply through heterogeneous individual responses to the environment, but also through variation in these environmental influences themselves.

\footnotetext{
${ }^{2}$ This view is similar to the "doing gender" perspective West and Zimmerman (1987), according to which - using a recent interpretation from England (2005, p. 269) - "each of us is held accountable to make sense to others in terms of gender norms, even if none of us actually prefer or believe in the rightness of the norms."
} 


\section{Life Course Timing in the Emergence of the Gender Gap}

Theories that give primacy to environmental influences tend to take a broader life course perspective on gender differentiation, but developmental psychologists also recognize that gender stereotypes elaborate throughout childhood and adolescence. Martin et al. (1990) found that by the age of 10, children have attached gender stereotypes to predominantly male occupations such as plumber or construction worker and to predominantly female occupations such as nurse or hairdresser. Liben et al. (2001) found that both 6-8 year old and 11-12 year old children are aware of the gendered character of occupations (see also McGee and Stockard 1991), and that children generally see male occupations (both familiar and fictitious) as higher status than female. Importantly, while meta-analyses suggest that gender stereotypes in general become less rigid after ages five or six (Signorella et al. 1993), the gender stereotyping of occupations became more pronounced as children aged into the 11-12 range in the Liben et al. (2001) study. These results suggest that the point of greatest salience to gender identity for particular roles or behaviors varies with the level of cognitive understanding of these behaviors and of their potentially gendered character. We expect this cognitive understanding to mature during the high school years, when students typically begin the study of more abstract mathematics and science, and when students begin to gain a sophisticated understanding of the world of work and its relevance to gender.

\section{The Local and Global Environment, and the Formation of Educational and Occupational Plans}

Both biological theories about gender and cultural theories that conceptualize culture as a coherent system of global norms and expectations imply that gender differences in the orientation towards STEM fields are relatively insensitive to variation in the local environment. In a similar vein, Xie and Shauman (1997) argued that occupational aspirations are formulated via cognitive processes that involve "the whole social environment at the societal level as the ultimate source of sex-typing." According to this model, environmental knowledge about gender is global in character (e.g., knowledge about sex typing of occupations in the global labor market) so that the global and not the local environment matters. They argued that "specific actors are viewed only as socializing agents of the larger environment $[\ldots]$ this cognitive process involves too many individuals for any single actor to play a dominant role" (pp. 238-239).

Other research traditions, however, emphasize the importance of actors in the local environment for the socialization process and for shaping occupational aspirations. Bussey and Bandura's social- 
cognitive theory, for example, claims that gender differentiation is shaped by the local environment through three specific influence processes: modeling, "enactive experience," (the positive or negative evaluations one obtains from the environment for one's behavior), and "direct tuition" (the conveyance of information about different behaviors and how they are linked to gender). The 1966 Coleman report (Coleman 1966), argued that the family is the most important determinant of achievement but also pointed at the importance of peers for performance in schools. The Wisconsin model of status attainment held that adolescents form their educational and occupational aspirations through socialization, with the major influence coming from parents, peers, and teachers (Hauser et al. 1983; Sewell and Hauser 1975; Sewell et al. 1969). More recently, the literature on stereotype threat and selfassessment asserts that the impact of gender and racial stereotypes on behavior depends on specific cues from the local environment (Aronson and Steele 2005; Good et al. 2008).

Based on these theories, we emphasize the importance of the local environment in constructing and reinforcing gendered beliefs and gender stereotypes. In particular, we argue that two processes shape the orientation towards STEM degrees among boys and girls and create variations in across local contexts. The first process concerns local influence from parents, teachers, and peers, and the second concerns curricular knowledge about STEM fields and STEM occupations.

First, we argue that peers, parents and teachers - all important actors in the local environment support and encourage certain career paths for boys and girls while disparaging others. Building on ethnographic studies (e.g. Francis 2000; an Ghaill 1994) that document the multiple strategies used by boys and girls to construct their own gender identities, Legewie and DiPrete (2011) have argued that local environmental variation in the support and sanctions for certain ways of 'doing gender' affects the size of the classroom and school-specific gender gap in academic performance. DiPrete and McDaniel (2011) have made a similar argument in regard to families, which suggests that the gender gap is smaller when boys grow up in a family that encourages a strong instrumental orientation and affective attachment to school as a means to achieve important life goals. Jacobs and Bleeker (2004) have found that parents influence the development of their sons' and daughters' interest in math and science by the extent of (frequently gendered) parental engagement in math and science activities during elementary school. Other studies have found that teachers can influence gender differences in orientation towards STEM for elementary school as well as college students (Habashi et al. 2009; Carrell et al. 2010). ${ }^{3}$ These considerations challenge Xie and Shauman's model of global environmental influence and argue that heterogeneity in math and science interests emerge not just from individual

\footnotetext{
${ }^{3}$ Park et al. (2011) recently found evidence that all-boys high schools increase the level of male interest in STEM fields in South Korea, but that all-girls schools do not have a corresponding effect on the proportion of females who major in STEM fields while in college.
} 
differences but from differences in the local environment, and in particular the school environment. These local variations influence the gender gap through the ways in which others perceive and treat boys and girls. But the local variations also exert influence by setting up expectations for appropriate preferences and behavior, and by the ways in which boys and girls perceive themselves and how they construct their own gender identities.

A second important aspect of the local environment is the availability of academic knowledge about STEM fields and of information about STEM careers. Information about occupations in adolescence is highly incomplete and therefore subject to local environmental variation. This variation is of potentially great importance for females, given that STEM fields -most notably in engineering and the physical sciences - are typically viewed as pathways to male careers. It is also important given the evidence from psychology that females tend to react more subtly to gender stereotypes than males in the process of forming interests in particular subjects and particular occupations. The greater level of subtlety opens the way for greater importance of the local environment in the extent of gender stereotyping of STEM occupations and fields of study, and its impact on the development of educational plans and occupational aspirations. As a consequence, we expect that knowledge about the actual character of science and mathematics will weaken gender stereotypes. Studies of high school curricula show wide variation in the extent and depth of course offerings in science and mathematics (Adelman 2006; Owings 1998). The high schools with the strongest science and mathematics curricular offerings arguably also offer the greater antidote to the discouragement of female interest in STEM fields due to gender stereotyping.

\section{Summary}

The above discussion argues that the process of forming gender stereotypes unfolds throughout adolescence, as tendencies toward greater flexibility in the development of gender stereotypes are either supported or inhibited by the particular character of the local school environment. The combination of imperfect knowledge about science and scientific professions and the different ways in which peers, parents and teachers shape gender stereotypes concerning science and scientific professions implies that the local environment can be of particular importance for the formation of individual orientations towards STEM fields. This local variation comes partly from variations in the (true or false) factual presentation of the association between gender and various aspects of STEM fields and STEM work, and partly from variations in how actors in the local environment such as peers, parents, and teachers influences individual orientation to STEM fields. In the following sections, we first document 
the importance of the high school years to the development of a gender gap in STEM orientations, then show how sensitive this gap is to the local high school environment.

\section{Pathways to a STEM Bachelor Degree}

To decompose the persisting gender gap in STEM degrees, we analyze data from the National Education Longitudinal Study 1988-2000 (NELS). NELS provides a large sample of eighth grade students, who were followed over time as they graduated from high school and entered the labor force or pursued post-secondary degrees. The panel structure of the data together with with the availability of detailed information on educational careers allows us to examine the educational paths that lead to a bachelor degree in STEM fields. We restrict our sample to students who participated in the eighth and twelfth grade surveys (base year and second follow up) and the 2000 follow up survey (fourth follow up). The size of this restricted sample is $8,320{ }^{4}$ From this sample, 1,260 (15.2\%) cases are dropped because of missing data on the relevant variables, which brings the analysis sample down to 7,060. All of the analysis use the appropriate weights provided by NELS. Appendix A provides further details about the sample restrictions and the variables used in the analysis.

Building on Xie and Shauman (2005, Cha. 4), we decompose the probability that an individual graduates from college with a STEM bachelor degree into different possible pathways as defined by transition rates between STEM orientations at three stages of the educational career. ${ }^{5}$ We use the orientation towards science and engineering in eighth grade as the origin state. ${ }^{6}$ This measure captures the pre-high school gender differences in orientation towards science and engineering. As the second stage towards a STEM BA, we use the expressed intention to study a STEM field in college at the end of high school (twelfth grade). As the third and final outcome stage, we use graduating from a four-year college with a STEM bachelor degree by 2000 (8 years after the expected high school

\footnotetext{
${ }^{4}$ All sample sizes are rounded to the nearest 10 (National Center of Educational Statistics requirement).

${ }^{5}$ Our decomposition extends Xie and Shauman's results (2005, Cha. 4) in important ways: First and most importantly, we incorporate eighth grade orientation towards science, which allows us to study how orientations towards science develop within as well as post-high school. Second, we analyze the pathways separately for the academically talented population because it is important to study transitions in terms of those who are in some meaningful sense "at risk" to major in science and engineering based on their preparation and ability. Third, we not only examine the pathways to a STEM degree in general, but also look at the pathway to a degree in specific STEM sub-fields. This extension is potentially important considering the vastly different trends for engineering, math, and physics on the one hand and biology and life science on the other hand (see Figure 1). Fourth, we update Xie and Shauman's results with more recent data. Their analysis is based on high school seniors from 1982 (High School and Beyond) while our analysis is based on seniors from 1992 (NELS). We find that the high school orientation is relatively more important and late entry transitions are relatively less important to the gender gap in STEM bachelor degrees than they reported. This difference is not an historical change between High School and Beyond and NELS; we find the same pattern in our reanalysis of High School and Beyond data as in the analysis of NELS data that we report on in this paper.

${ }^{6}$ The orientation during eighth grade is measured using the occupational expectation by age 30 . Respondents were asked 'What kind of work do you expect to be doing when you are 30 years old?' and one of the response categories was 'Science/Engineering' (5.8\%), which we used to define a science and engineering orientation in eighth grade.
} 


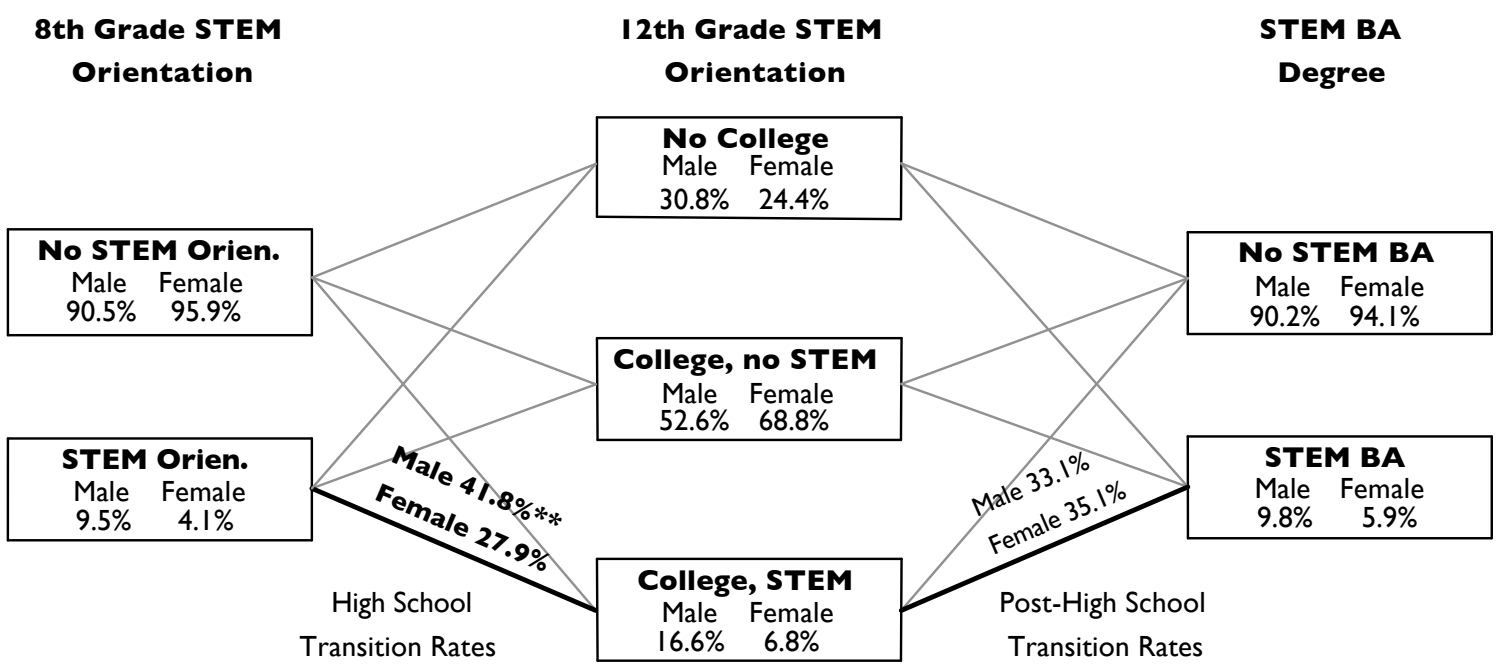

Figure 2: Persistence in the Pathway to a STEM BA Degree

Source: National Education Longitudinal Study, 1988-2000

Note: Asterisks $\left({ }^{*} \mathrm{p}<0.05,{ }^{* *} \mathrm{p}<0.01\right)$ and bold font indicate whether the gender difference in a specific transition rate is significant.

graduation date). Figures 2, 3, and 4 all show the same distribution of these three states for boys and girls but highlight different components of the transitions that produce the gender gap in STEM bachelor degrees. In particular, Figure 2 shows the pathway of persistence, which is defined as a continuing science and engineering orientation from one state to the next. The leakage pathway shown in Figure 3, in contrast, is defined as having a science and engineering orientation in one state but not the next. Finally, Figure 4 shows the gender gap in late entry, which is defined by transfer from a non-science orientation in one state to a science orientation in the next state. We calculate these transition rates within high school (high school transition rates) as the probability of each twelfth grade state conditional on the eighth grade orientation, and we calculate post-high school transition rates as the probability of obtaining a STEM BA conditional on the orientation at the end of high school. This decomposition allows us to examine at what stage of the life course gender differences in the orientation towards science and engineering emerge, and at what point these differences become stable and have lasting implications. ${ }^{7}$

The results presented in all three figures show a substantial gender gap in eighth grade orientation towards science and engineering. Boys are more than twice as likely as girls to expect to work in science or engineering in middle school (9.5\% compared to $4.1 \%)$. This finding is in line with earlier studies reporting gender differences in the orientation towards and perception of math and science

\footnotetext{
${ }^{7}$ For simplicity, we do not distinguish between respondents who did not graduate from college and those who graduate with a non-STEM major. We thereby simplify the decomposition to exclude gender differences in rates of STEM bachelor degrees that arise from gender differences in the probability of getting a BA.
} 


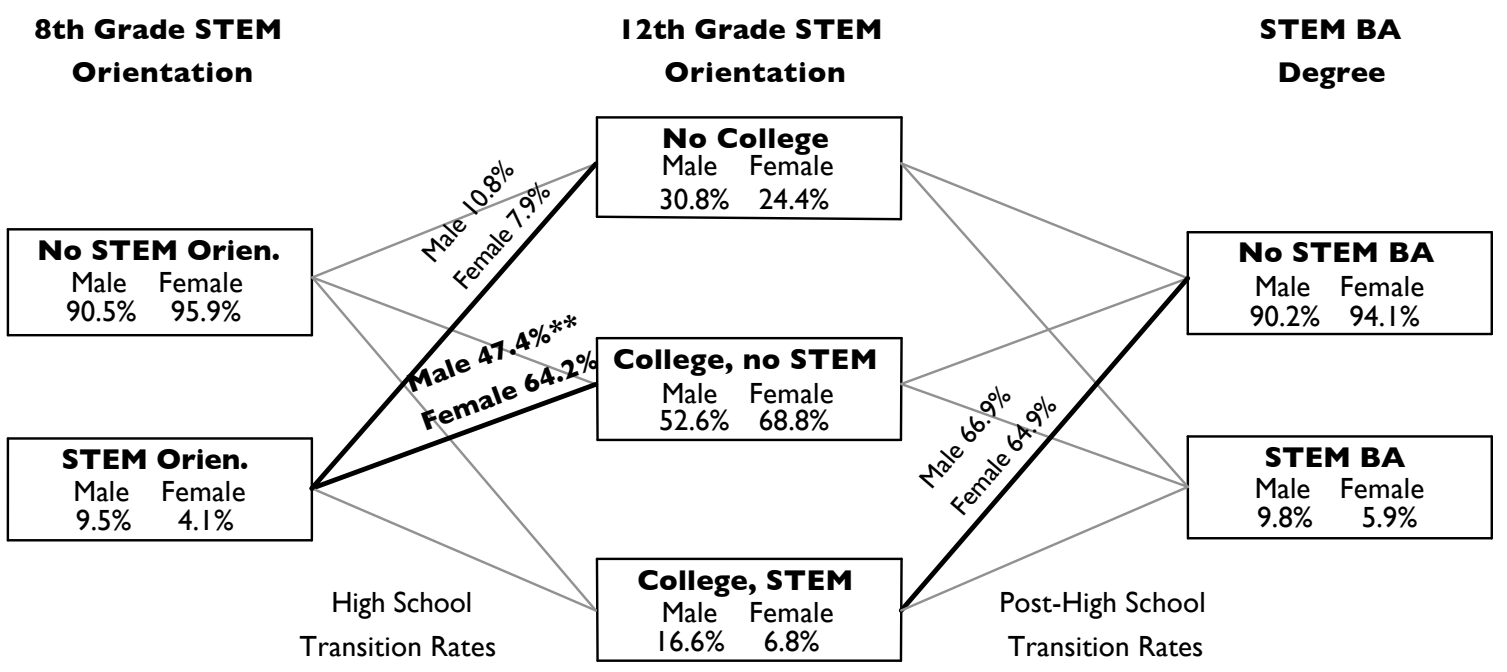

Figure 3: Leakage from the Pathway to a STEM BA Degree

Source: National Education Longitudinal Study, 1988-2000

Note: Asterisks $\left({ }^{*} \mathrm{p}<0.05,{ }^{* *} \mathrm{p}<0.01\right)$ and bold font indicate whether the gender difference in a specific transition rate is significant.

from early childhood to adolescence (Jacobs et al. 2002). Comparing Figures 2 and 4, we see that eighth grade STEM orientation predicts twelfth grade STEM orientation for both boys and girls. Thus, $41.8 \%$ of males with an eighth grade STEM orientation have a twelfth grade STEM orientation (persistence), as compared with only $13.9 \%$ of males who lacked an eighth grade STEM orientation (late entry). Similarly, $27.9 \%$ of females with an eighth grade STEM orientation have a twelfth grade STEM orientation, as compared with only $5.8 \%$ of females who lacked a STEM orientation in eighth grade. Accordingly, boys are more likely to persist in and enter a science orientation during the high school years than are girls ( $41.8 \%$ compared to $27.9 \%$ for persistence and $13.9 \%$ compared to $5.8 \%$ for late entry; see Figure 2 and 4). The gender gap in persistence rates, however, disappears after high school. In other words, once high school seniors have developed an orientation towards science and engineering, boys and girls are equally likely to pursue this orientation after high school and actually graduate from college with a STEM BA (33.1\% compared to $35.1 \%$, the difference is not statistically significant). The same pattern is shown in Figure 3 in terms of leakage rates. It shows that girls are more likely to change their orientation from a STEM to a non-STEM orientation from eighth to twelfth grade ( $64.2 \%$ for females; $47.4 \%$ for males), whereas these leakage rates are the same for the post-high school period (64.9\% for females, $66.9 \%$ for males). The gender gap in late entry, however, remains substantial even in the post-high school period so that boys are more likely to be recruited for STEM field both during the high school years as well as after graduating from high school. Thus, the results in Figure 4 show pronounced (and highly significant) gender differences in the rate of entry 


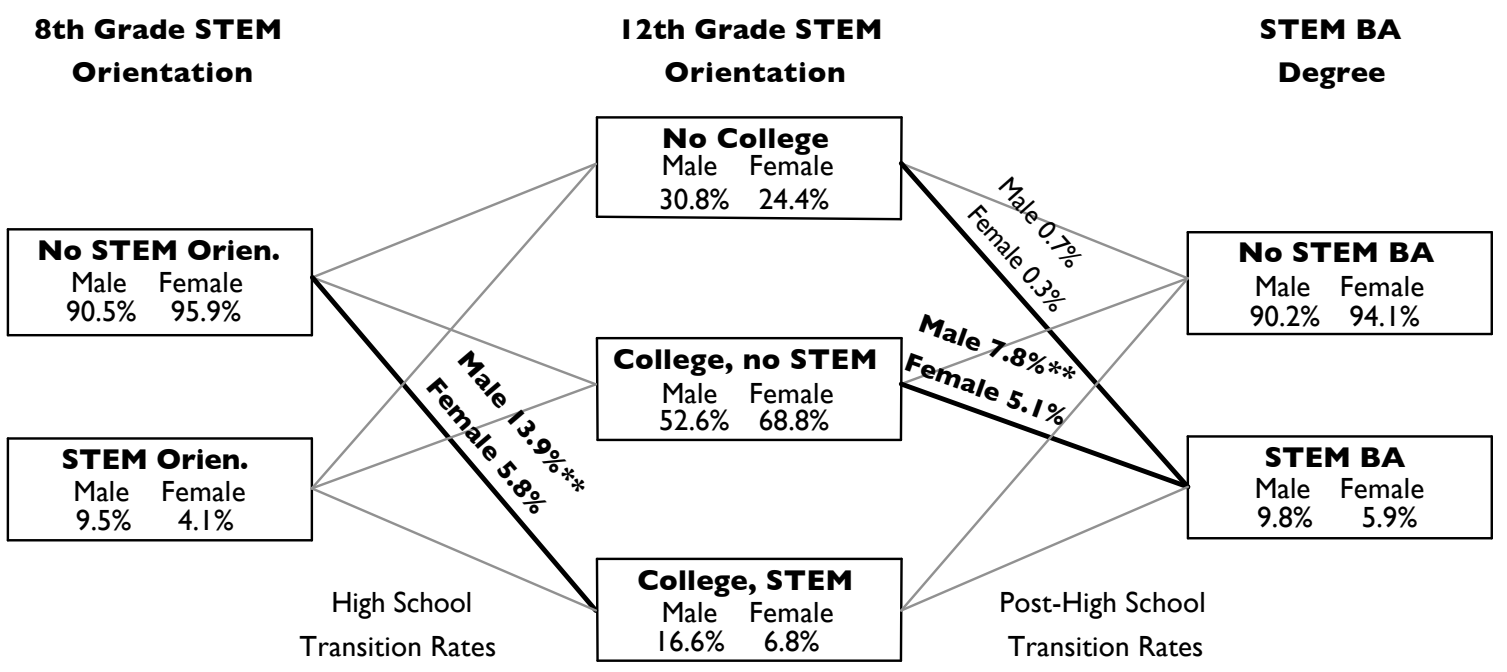

Figure 4: Late Entry as a Pathway to a STEM BA Degree

Source: National Education Longitudinal Study, 1988-2000

Note: Asterisks $\left({ }^{*} \mathrm{p}<0.05,{ }^{* *} \mathrm{p}<0.01\right)$ and bold font indicate whether the gender difference in a specific transition rate is significant.

into the science track for both the high school and the post-high school transitions rates.

Overall, these gender differences in initial eighth grade distributions and in the three transition rates of persistence, leakage, and late entry lead to a substantial gender gap in STEM degrees by the end of college: only $5.9 \%$ of female college graduates obtained a STEM bachelor degree, as compared with $9.8 \%$ of males. To determine the contribution of the different components of the decomposition to the overall gender gap, we successively assigned women the male orientation distribution as of eighth grade and the various male transition rates, and calculated how the gender gap would change under these hypothetical scenarios. Table 1 shows the results from these simulations. They show that the science orientation during eighth grade only plays a marginal role even though we observed a substantial gender gap in the orientation towards science during eighth grade. In particular, the gender gap would be reduced by $10.5 \%$ if women had the same eighth grade science orientation as men. The reason for this slight importance of pre-high school orientation is the role of the high school years in shaping the science orientation of boys and girls. If males and females had the same transition rates within high school, the gender gap in STEM BAs would be reduced by a substantial $55.3 \%$. The combination of eighth grade orientation and within-high school transition rates mathematically identify the twelfth grade science and engineering orientation, which accounts for $68.5 \%$ of the gap (i.e., $68.5 \%$ of the gap would disappear if women had the same twelfth grade orientation as men). Post-high school transition rates, and in particular gender differences in the rate of late entry into the science track, play the second most important role for the gender gap and account for $47.1 \%$ of the 
Table 1: Decomposition of Gender Gap in STEM BAs, NELS 1988-2000

\begin{tabular}{|c|c|c|c|c|}
\hline Percent with STEM BA Degree & Male & Female & $\begin{array}{c}\text { Gender } \\
\text { Gap }\end{array}$ & $\begin{array}{c}\text { Percent } \\
\text { Reduced } \\
\text { (Personal) }\end{array}$ \\
\hline Observed & 9.83 & 5.98 & 3.84 & \\
\hline \multicolumn{5}{|l|}{ Changes if Females are Assigned Male Values } \\
\hline Same 8th Grade Orientation & & 6.38 & 3.44 & 10.45 \\
\hline Same 12th Grade Orientation & & 8.61 & 1.21 & 68.51 \\
\hline Same HS (8th $\rightarrow 12$ th) Transition Rates & & 8.11 & 1.72 & 55.31 \\
\hline Same HS Late Entry & & 8.7 & 1.12 & 70.8 \\
\hline Same HS Persistence & & 6.18 & 3.65 & 5.17 \\
\hline Same Post-HS (12th $\rightarrow$ BA) Transition Rates & & 7.79 & 2.03 & 47.1 \\
\hline Same Post-HS Late Entry & & 7.93 & 1.9 & 50.66 \\
\hline Same Post-HS Persistence & & 5.84 & 3.98 & -3.56 \\
\hline Same Late Entry Rates & & 10.65 & -0.82 & 121.46 \\
\hline Same Persistence Rates & & 6.03 & 3.79 & 1.31 \\
\hline
\end{tabular}

Note: Late Entry refers to the transition rate from no science orientation in eighth grade to science orientation at the end of twelfth grade as well as the transition rates from 'no college' and 'college, non-STEM' in twelfth grade to a STEM BA. Persistence refers to the transition rate from science orientation in eighth grade to science orientation in twelfth grade and from there to a STEM BA.

gap.

In Appendix B, we also present the same results for the subset of academically talented students, and for different STEM subfields, which seems particularly important considering the substantial differences in the trends for STEM subfields shown in Figure 1. As it turns out, the results from these additional analyses closely resemble the findings for the overall gender gap reported above.

In sum, the results suggest that the gender differences in transition rates during the high school years play a decisive role in shaping personal orientations toward science. During these years, girls are much more likely to abandon a science career even when they expressed interest in eighth grade, and boys are much more likely than girls either to persist or to enter a science and engineering oriented educational path. The importance of the high school years is also reflected in the high proportion of the gap accounted for by gender differences in the transition rates. As suggested by our theoretical argument, this finding points at the importance of social factors in explaining the gender gap in STEM BAs insofar as these theories do not imply that gender differences get entrenched early in the life course but instead develop and change throughout adolescence. The second most important component for the gender gap in STEM BAs is gender differences in the entry into the science track after high school. Once graduated from high school, girls are much less likely to change from a non-STEM orientation to a STEM major. 


\section{The Role of High School for the Gender Gap in STEM Orientation}

The last section demonstrated our first central contention that the high school years play a crucial role in shaping the orientation towards science and engineering among boys and girls. We now examine the role of high school context for shaping orientations towards science and engineering during this decisive period. In particular, we use multilevel models to document how the gender gap in STEM orientation at the end of high school varies across high schools, and estimate the causal effect of the high school curriculum on the gender gap in STEM orientation. For this purpose, we use two special samples from the National Education Longitudinal Study. Compared to the 1988 to 2000 panel study (NELS 88-2000), these two special samples only follow the students until their senior year in high school, but they offer important advantages for our analytic goals. NELS 88-92 includes the full eighth grade sample of NELS $(\sim 25,000)$, which is a much larger sample than NELS $88-2000^{8}$, as well as important pre-high school variables about the early science and engineering orientation. The NELS 88-92 sample does not, however, generally include a large number of students per high school because eighth-grade students in the same school typically transitioned to more than one high school. The NELS High School Effectiveness Study (HSES), which is the second dataset we use in the following analysis, addresses this problem. As an independent component of NELS, the HSES extended the sample of students in a subset of 250 high schools in the first follow-up 1990 so that these schools had a sufficiently large number of students per school to support our analytic strategy. In contrast to NELS 88-92, however, HSES does not include pre-high school information. The sample restrictions for both datasets, the multiple imputation procedure used to recover missing data, and the variables are described in Appendix A.

In the following analysis we use both NELS 88-92 and HSES to study the variation of the gender gap across schools conditional on regional and urban variations. For this purpose, we specify a logistic multilevel model that captures variation in the gender gap in twelfth grade STEM orientation across schools. The outcome variable is the STEM orientation in twelfth grade at the end of high school. A value of 0 indicates that a student does not intend to study a STEM field in college after graduating from high school, whereas a value of 1 indicates that students intend to study a STEM field after high school. The results from this analysis show substantial variation in the gender gap across high schools even after controlling for a comprehensive set of pre-high school covariates. This finding, described in more detail over the next paragraphs, indicates that the high school context plays an important role

\footnotetext{
${ }^{8}$ Only a randomly selected subset of students were followed after high school.
} 


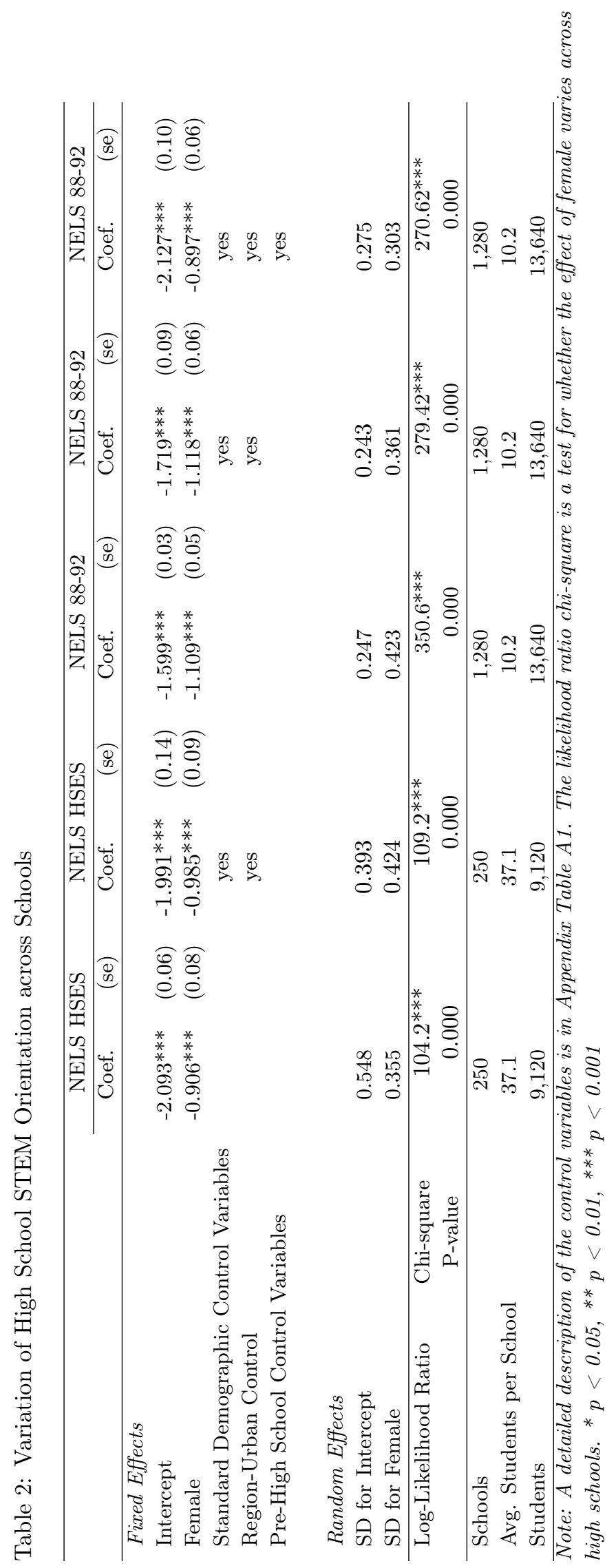


in shaping the gender gap in STEM orientation.

We begin with a simple model that only includes female as an independent variable along with a random intercept and a random slope at the school level that allows the effect of gender on high school STEM orientation to vary across high schools. The results from this multilevel model fitted with the HSES as well as the NELS 88-92 data are presented in Table 2. The estimated coefficients show a substantial gender effect; the odds of reporting an intention to study a STEM field in college at the end of high school for female are about 60\% (HSES) or 70\% (NELS 88-92) lower than the odds for males (the female/male odds ratio are 0.4 and 0.3 as calculated from the coefficients on the log-odds scale reported in the table). The results in the last section showed that this substantial gender gap at the end of high school is decisive for the later gender gap in STEM bachelor degrees, accounting for nearly $70 \%$ of the gap. The gender gap in personal STEM orientation, however, varies substantially across high schools. Specifically, the estimated standard deviation of the random effect on the school level implies that the gender gap ranges from 0.20 to 0.82 female/male odds ratios in the middle $95 \%$ of schools (these are the more conservative estimates from a HSES dataset). In other words, the odds for girls having a STEM interest are only $18 \%$ lower than the odds for boys in schools at one end of this spectrum, whereas in schools at the other end the difference is $80 \%$. This variation is illustrated in Figure 5, which shows the distribution of the empirical Bayes estimates for the 250 high schools in HSES and the 1,280 high school in NELS 88-92. The graph also illustrates the analytical limitations of the NELS 88-92 dataset: Even though the estimated random slope for the variation of the gender effect across schools is bigger in NELS 88-92 than in HSES, the empirical Bayes estimates do not vary as strongly. The reason for this difference is the smaller average number of students per school in NELS 88-92. Empirical Bayes estimates are so-called "shrinkage" estimates; they are a weighted sum of the estimates from a single school and the estimates predicted for that school by data for the larger population (which is the prior information from a Bayesian perspective). Empirical Bayes estimates for schools with a large number of students put more weight on the school-specific estimate, while empirical Bayes estimates for schools with a small number of students put more weight on the overall gender gap so that their estimates are pulled more strongly towards the overall mean (for a discussion of this see Gelman and Hill 2007). Despite considerable shrinkage towards the overall mean, the NELS 88-92 data do contain enough students per school to reveal substantial variation (from 0.3 to 0.45 for the female/male odds ratio) in the gender slope across schools.

The revealed variation in the gender gap across schools might reflect the importance of the local school context, but it is also possible that they arise from a non-random sorting of students into different high schools such that girls with a strong science orientation are more likely to go to one 

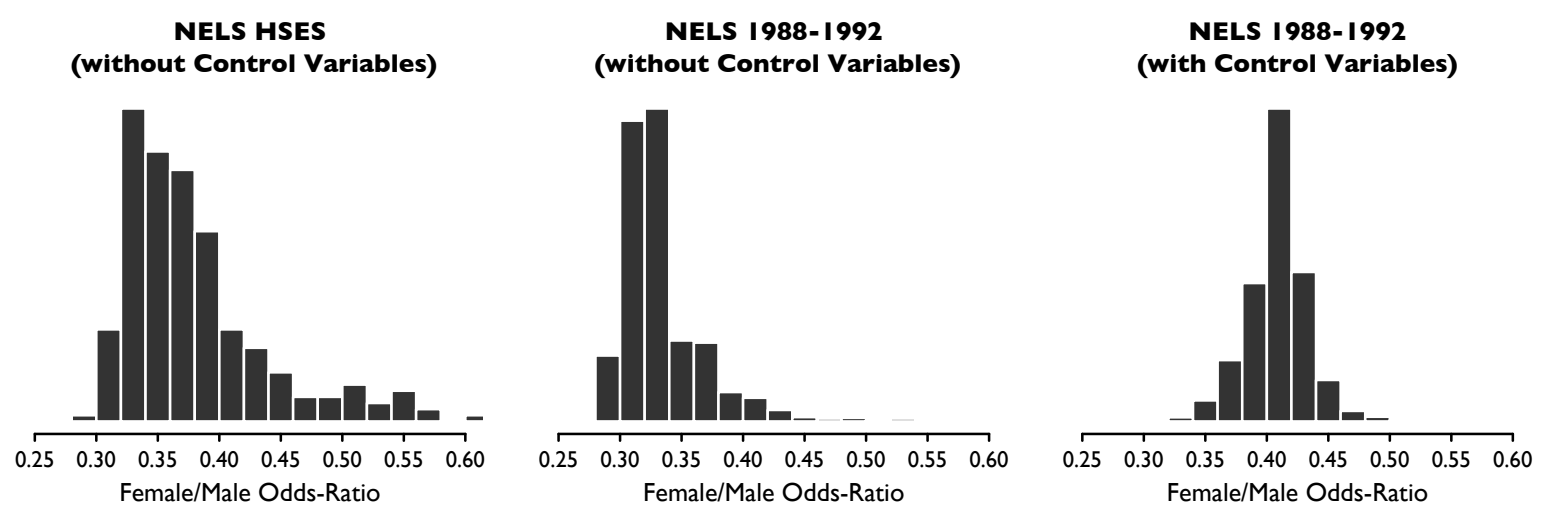

Figure 5: Variation of Gender Gap in 12th Grade STEM Orientation across Schools, NELS 1988-92 Note: The graph reports female/male odds-ratios so that a value of 1 indicates gender equality and values closer to one-i.e. higher values in this graph-a smaller gender gap.

school rather than another. In order to address this problem, we first add a number of standard demographic measures and a categorical region-urban variable to both the HSES and the NELS 88-92 and then use the NELS 88-92 sample to also condition on a large number of eighth grade orientation and performance measures (the variables are described in Appendix Table A1). We thereby obtain an estimate of the high school effect on science and engineering orientation that is conditional on the pre-high school science and math orientation as well as performance of students. The eighth grade orientation measures include not only the expressed occupational plans of eighth grade students used in the pathway analysis, but also four measures that assess whether middle school students like math and science and whether they think that math and science is important for their future. The performance measures are comprehensive and include three eighth grade test scores (math, science, and English), and four GPA measures (math, science, English, and social studies). Because of this comprehensive set of control variables for family background, region-urban, pre-high school science and engineering orientation, and academic performance, these models can be understood as 'value-added' models for STEM orientation. Similar to value-added models in educational research on the effect of schools and teachers on performance (e.g., Kane and Staiger 2008), the empirical Bayes estimates from these models show the extent to which schools vary in supporting a science and engineering orientation among high school students, conditional on their previous orientation. They also show the extent to which schools are particularly supportive or unsupportive of a science orientation for girls net of the school's support for a science orientation for boys.

The results from these models are presented in Table 2 as well as Figure 5. They show that although the estimated standard deviation for the school variation is smaller after pre-high school variables are controlled, the remaining variation in the effect of the local environment is still substantial and 
statistically significant. In particular, the estimated random slope from the multilevel model suggests that the gender gap ranges from 0.22 to 0.75 female/male odds ratio in $95 \%$ of the schools. Figure 5 shows the distribution of the empirical Bayes estimates, which indicate substantial variations across schools (the female/male odds ratio ranges from 0.34 to 0.50 ) despite the considerable pooling towards the overall mean in the NELS 88-92 sample .

Overall, the results presented so far show substantial variation in the gender gap in science and engineering orientation across schools. Net of science and math orientation in eighth grade, high schools appear to play an important role in shaping these orientation among boys and girls. This finding provides support for our argument that the local as well as the global environment shapes the gender gap in orientation towards STEM fields. It remains unclear, however, which particular characteristics of the high school explain these variations. In the remaining part of this section, we begin to explore this question and also address two important follow-up questions.

\section{The Effect of High School Curriculum on the Gender Gap in STEM Orien- tation}

The analyses so far have demonstrated the importance of the high school years for the persisting gender gap in STEM degrees, and have shown substantial variation in the gender gap in STEM orientations across high schools, net of pre-high school orientation. In this section, we estimate the causal effect of the math and science curriculum in high school on the STEM orientation in twelfth grade for boys and girls. This analysis helps us to understand the variations across the local school environment, which is highly relevant from a policy perspective. Based on the theoretical argument developed above, we would argue that a math and science orientation in high school as reflected in the course offerings in math and science has a positive effect on the STEM orientation for both boys and girls, and that the effect should be especially large for girls. We expect the strength of gender stereotypes about occupations to vary inversely with the level of information about these careers provided by the local environment, and about the relevance of gender to success in these careers. Given that girls currently perform at the same level as boys in advanced math and science high school courses, we expect that experiential knowledge of this fact and of the actual character of science and mathematics - as revealed in advanced coursework - will weaken gender stereotypes and lead to a reduced gender gap in STEM orientation during high school.

In order to estimate the causal effect of the math and science curriculum in high school, we use the fact that the original NELS sample was first interviewed in eighth grade before students 
attended high school. This feature of the data allows us to condition on the same comprehensive set of pre-treatment variables used before. These variables are directly related to the selection of students into high schools with a strong math and science curriculum. A number of recent studies that compare experimental results with regression and matching estimates have shown that such a comprehensive set of pre-treatment variables is essential to reduce the bias in estimates that are based on regression or matching methods (Cook et al. 2009; Shadish et al. 2008). These studies also suggest that the actual method used to estimate the effect - regressions based on the raw data or based on a matched sample - plays a negligible role relative to the importance of the right pre-treatment controls and despite the theoretical advantages of matching (for corroborating arguments, see Angrist and Pischke 2008). Accordingly, the estimates presented below are based on logistic regressions using a comprehensive set of pre-treatment control variables from eighth grade, including not only standard demographic measures but also the eighth grade orientation towards math and science, the extent to which a student reports that s/he likes math and science, and a set of seven GPA and test score performance measures for reading, math and science (for a detailed description of the variables see Appendix Table A1). The focal treatment variable is the intensity of the high school course offerings in math and science. We measure this variable based on a set of questions asked in the tenth grade school questionnaire about the courses offered at a school. In particular, we create an index based on the AP or college or university level course offered for 31 different math and science areas such as biology, physics, life science, calculus, and trigonometry, and we standardize this index with a mean of zero and a standard devision of one. Appendix C contains a detailed description of the estimation strategy, the sample, the variables and an assessment of the balance between different levels of the treatment indicator.

Table 3 presents estimates of a STEM orientation at the end of high school from logistic regressions on the curriculum index for boys and girls conditional on a large set of pre-treatment covariates. The table shows separate estimates for students who did not indicate a science orientation in eighth grade and for those who did. Accordingly, the table shows both estimates for the probability of late entry into the science track during high school as well as for the probability of persistence in the science track during high school. Our prior analysis revealed a substantial gender gap in both the late entry and the persistence rate, but also indicated that the difference in male and female rates of late entry by gender (which can be understood as the ability of a high school to recruit boys and girls into the science track) plays a decisive role in gender gap in STEM degrees. The results for late entry in table 3 show a substantial gender gap in the late entry rate as previously observed. In particular, boys are 2.3 times as likely as girls to transfer into a science track during high school (male/female odds ratio). 


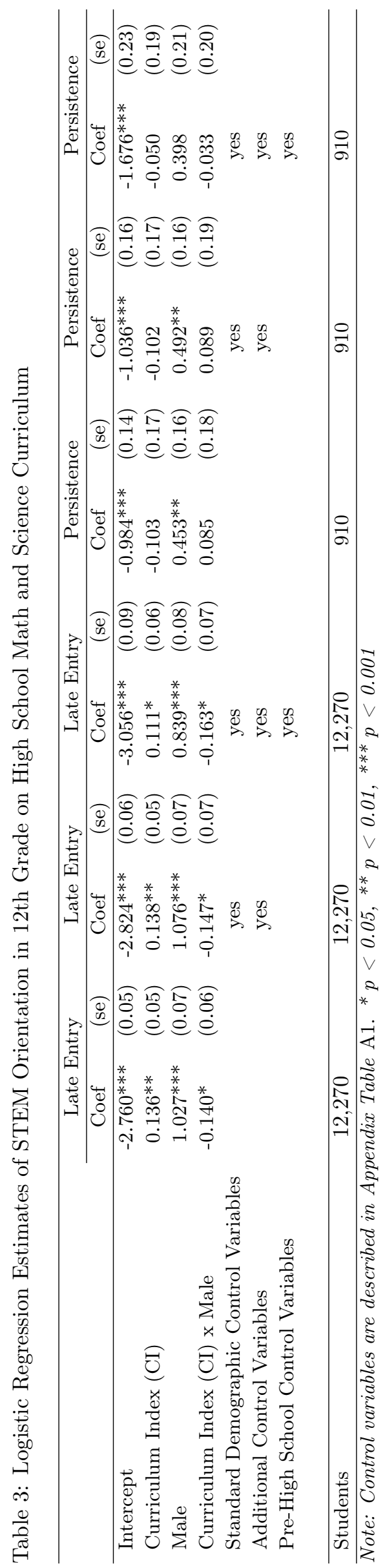




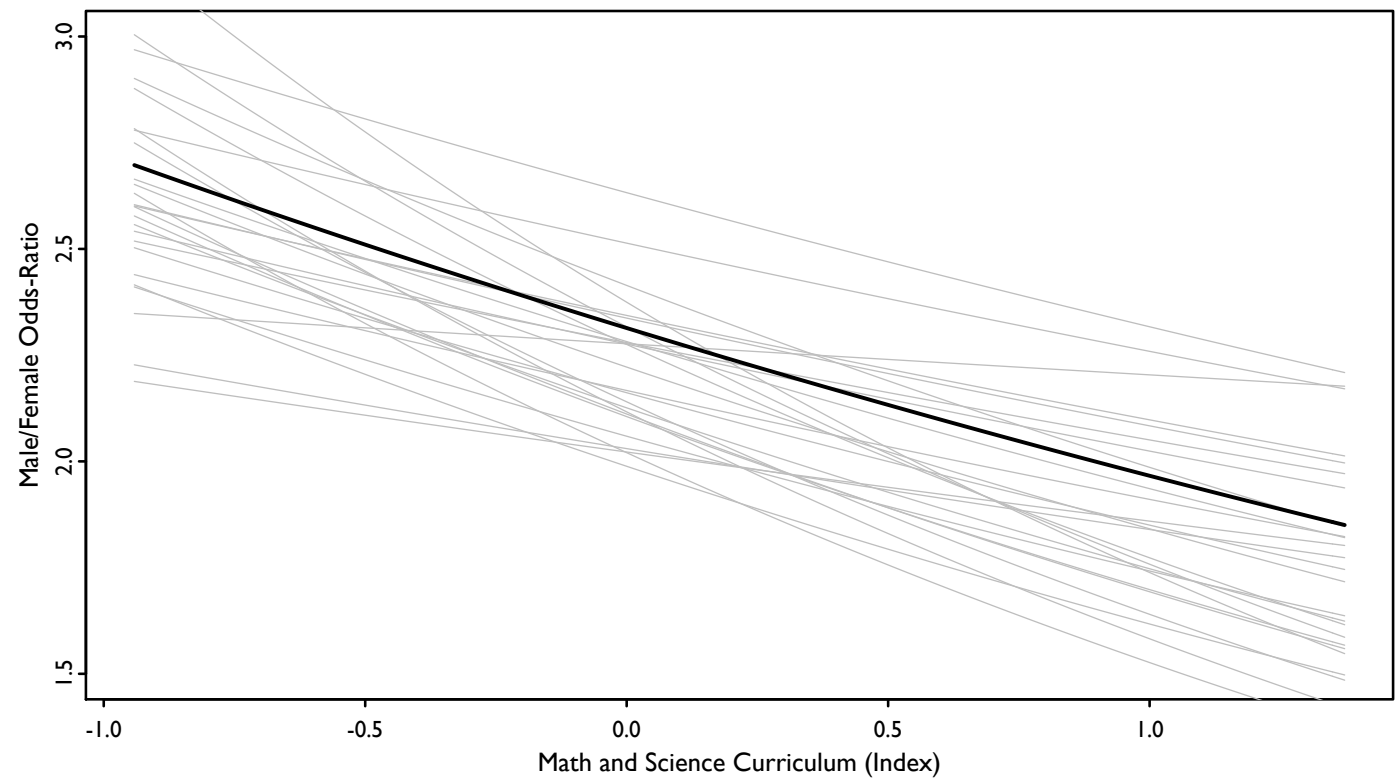

Figure 6: Effect of High School Curriculum on STEM Orientation

Note: The graph shows the gender gap in the entry into a science track during high school in terms of the male-female odds ratio as a function of the intensity of the math and science curriculum (estimates from third late entry model in Table 3). The graph covers the range between the 10th and the 90th percentile of the math and science curriculum index. The grey lines visualize the uncertainty in the estimated interaction effect based on 25 simulations (Gelman and Hill 2007, 140).

Consistent with our hypothesis, the results also show that the curriculum index has a substantial effect on the late entry rate for girls but not for boys. The estimated effect (in units of odds ratios) is 1.12, which implies that a one standard deviation change on the scale of the high school's math and science curriculum index produces a $12 \%$ greater increase in the odds that a girl will transition from a nonscience to a science orientation than in the corresponding odds for a boy. This result was obtained after controlling for a comprehensive set of pre-treatment control variables for STEM orientation, academic performance, and other variables, and is stable across different model specifications. As a consequence of this interaction between curriculum and gender, the gender gap in STEM orientation narrows in high schools with a strong math and science curriculum, net of pre-treatment controls. Figure 6 illustrates this finding graphically and shows how the gender gap in terms of the male-female odds ratio in STEM orientation at the end of high school is smaller in schools with a strong math and science curriculum (the graph covers the range between the 10th and the 90th percentile of the math and science curriculum index). While this finding might still be affected by unobservable variables that are related to the treatment and the outcome after controlling for observed pre-treatment controls, the strong set of pre-treatment control variables available in NELS increases our confidence in the findings. 
The logistic regression results for persistence, however, do not show a gender difference in the effect of the math and science curriculum. The estimated effect is both substantially smaller and statistically insignificant, which implies that the high school math and science curriculum mainly works through its power to recruit girls into science and engineering and not through its power to retain girls in science who have previously reported a STEM orientation. This pattern of results is consistent with the findings from our pathways model. The gender gap in STEM BAs is not primarily a consequence of girls losing their personal STEM orientation at a greater rate than boys, but rather from the lower rate of recruitment of girls into a STEM orientation between eighth grade and the senior year of college.

\section{Is the High School Effect Lasting?}

A common argument in the debate on the the effect of teachers on the learning of students is that potential gains in performance abate over the following years (Rothstein 2010; Jacob et al. 2010). A similar concern should apply to the effect of high school on the science and engineering orientation of boys and girls. If girls who were enrolled in high schools that were especially good recruiters of girls into a personal STEM orientation were to leak from the science pipeline at higher rates, the school effect would not be an important determinant of the gender gap in STEM bachelors degrees. In a recent review of interventions to increase female interest in science and technology (e.g., Turner and Lapan 2005; Plant et al. 2009), Hill et al. (2010) noted the uncertainty about the long term effects of these interventions that arises simply from the lack of long-term followup data. In this respect, the NELS data are attractive because they allow a direct assessment of the durability of high school effects on STEM orientations.

In order to conduct this assessment, we group high schools by the size of the gender gap in science and engineering orientation and examine the post-high school transition rates used in the pathway analysis above. In particular, we use the empirical Bayes estimates of the gender gap from the 'valueadded' multilevel model (NELS 88-92) above to group schools into those with a small gender gap (bottom terciles) and those with a big gender gap (top terciles). We then match this newly created school-level variable to the students in NELS 88-2000 and calculate the post-high school transition rates separately for the full school sample (already shown in the graphs above) as well as the high schools with a small and big gender gap.

Table 4 presents the results from this analysis. It shows that the post-high school transition rates are remarkably constant across the three samples. Neither of the transition rates differs significantly 
Table 4: Post-High School Transition Rates for Full Sample, and School with Small/Big Gender Gap

\begin{tabular}{llccc}
\hline $\begin{array}{l}\text { Post-HS Transition } \\
\text { Rates }\end{array}$ & Gender & Full Sample & $\begin{array}{c}\text { Schools with Small } \\
\text { Gender Gap }\end{array}$ & $\begin{array}{c}\text { Schools with Big } \\
\text { Gender Gap }\end{array}$ \\
\hline Leakage Rate & male & 0.669 & 0.615 & 0.692 \\
\multirow{2}{*}{ Late Entry Rate } & female & 0.649 & 0.686 & 0.637 \\
& male & 0.078 & 0.084 & 0.082 \\
Persistence Rate & female & 0.051 & 0.06 & 0.039 \\
& male & 0.331 & 0.385 & 0.308 \\
& female & 0.351 & 0.314 & 0.363 \\
\hline Note: Late Entry refers to late entry from a college but non-STEM orientation at the end of high school.
\end{tabular}

between the three samples. Accordingly, students from high schools that encourage a science and engineering orientation among women do not have higher leakage rates from the science pipeline than their peers from schools with a big gender gap. This finding suggests that the effect of high schools on the science and engineering orientation of women is not temporary, but instead endures after high school and ultimately reduces the gender gap in the attainment of STEM BAs. Accordingly, high schools seem to be an effective agent for policy initiatives to reduce the gender gap in STEM degrees.

\section{How Much does the High School Effect Matter?}

Building on the findings from the last section, we ask how much the gender gap would be reduced if all schools would encourage women to study science and engineering at the same rate as schools in the bottom tercile of the gender gap. For this purpose, we again group high schools into terciles according to the size of their gender gap in STEM orientation. We then calculate the gender gap in STEM BA degrees assuming the same eighth grade orientation and post-high school transition rates across all three samples. In other words, we assume that differences in the gender gap across the three samples only emerge because of differences in the transition rates within high school, and not from group differences in eighth grade orientation and transition rates after high school. As shown in Table 5, boys are 1.7 times as likely as girls to graduate from college with a STEM BA degree in the entire sample. However, this substantial male advantage is reduced to 1.3 (male/female odds ratio) in the sub-sample of students who attend high schools with a small gender gap. Accordingly, the gender gap would be reduced by about $25 \%$ if the environment in all schools would encourage girls to study science and engineering at the same rates as the top third of schools. The reduction would presumably be even larger if all schools could achieve the same results as the most gender-egalitarian schools in our sample. 
Table 5: Gender Gap in STEM BAs for Full Sample, Schools with Small Gender Gap, and Schools with Big Gender Gap

\begin{tabular}{lcccc}
\hline Proportion of Students with & & \multicolumn{2}{c}{ Gender Gap } \\
\cline { 4 - 5 } STEM bachelor degree & Male & Female & in \% & Odds Ratio \\
\hline Full Sample & 0.098 & 0.060 & 0.038 & 1.713 \\
Schools with Small Gender Gap & 0.124 & 0.095 & 0.029 & 1.349 \\
Schools with Big Gender Gap & 0.077 & 0.039 & 0.039 & 2.089 \\
\hline
\end{tabular}

\section{Conclusion}

Despite the striking reversal of the gender gap in educational attainment and the near gender parity in math performance, women still pursue science, technology, engineering, and math degrees at much lower rates than their male peers do. In this paper, we have explored two important and related dimensions of this persisting gender gap in STEM degrees: First, the timing in the emergence of the gender gap in orientation towards STEM fields, and second, variations in the gender gap across high schools. Based on an examination of biological, psychological, and sociological theories about gender, we have argued that the process of forming gender stereotypes unfolds throughout adolescence, and that the local high school environment plays an important role in shaping the gender gap. We then turned to an empirical examination of the two dimensions. First, we decomposed the gender gap in STEM bachelor degrees into various pathways to examine the emergence and solidification of gender differences in the orientation towards science and engineering in the adolescent life course. In particular, we used the National Education Longitudinal Study to follow the 1988 cohort of eighth grade students through adolescence and young adulthood, and we observed how orientations towards STEM fields emerge and change during these years. Our findings show that the substantial gender gap in eighth grade orientation is relatively inconsequential for the persisting gender gap in STEM degrees at the completion of college. Instead, the high school years play a major role in shaping gendered orientations towards science and engineering. Second, we used multilevel models to examine how the gender gap in STEM orientation at the end of high school varies across schools, net of pre-treatment controls. The results show substantial variation in the gender gap in STEM orientation across schools, and support our argument that the local environment plays a major role in shaping and gendering orientations towards education and career among boys and girls. Our additional analyses show that this high school effect seems to be related to the math and science orientation of the school.

Existing theories of the persisting gender gap in STEM degrees focus on gender differences in mathematical ability as well as women's lack of interest in STEM degrees, and point at biological, psychological, and sociological theories to explain these differences. While the analyses conducted in 
this paper are not designed to provide a definitive test for any of the theories, the results nonetheless have important implications for the existing debate. Our findings identify adolescence as the crucial period in life when the gender gap in orientations towards STEM fields solidifies at the individual level. They argue against gender essentialist theories and instead support theoretical accounts for gender segregation in science and mathematics fields of study that emphasize the importance of the local environment in shaping the gender gap in STEM degrees. These include social-cognitive theories from psychology, and sociological theories which emphasize local environmental influence on the construction and salience of gender stereotypes, status expectations, and career aspirations. In this respect, our results parallel recent research which shows that academically-oriented classroom and peer cultures in late elementary school have especially strong effects on the academic performance of boys (Legewie and DiPrete 2011). Legewie and DiPrete's results suggested that learning-oriented academic climates in school counteract masculine stereotypes that favor an oppositional attitude towards school and thereby undermine the educational performance of boys. In both that study and the current one, greater investment in the school climate works to mitigate the negative consequences of gender stereotypes (in one case involving females and the other case involving males) that undermine the educational process.

Not all local environmental effects are necessarily durable, of course. Indeed, recent research on social-psychological interventions in education to counter racial or gender stereotypes have triggered an active debate about whether the effects in question are real, scalable, or long-lasting (Yeager and Walton 2011). High school context is, of course, a much more intensive and extensive "treatment" than are the targeted interventions found in the social-psychological literature on stereotype threat. However, in light of recent research asserting only a temporary effect from exposure to Head Start programs or to individual above-average teachers (Jacob et al. 2010), it is of considerable importance that the effects of the high school environment on the formation of STEM orientations appear to be durable. Our findings, therefore, have important policy implications. The pathway analysis shows that high school is the decisive life period during which the gender gap emerges, and the examination of variations across contexts shows that the local context in high school plays an important role for the gender gap in orientations towards STEM fields. As such, our findings not only point at the life course period that should be targeted by policy interventions, but also provide evidence that high school interventions might be effective. Some existing interventions have targeted high school students and shown success in promoting a STEM orientation among girls. Eisenhart (2008), for example, discusses a seemingly effective outreach project that educates high-achieving, minority girls in high school about science and engineering jobs. While such policy interventions have to withstand the serious scrutiny of 
experimental field trials, the evidence presented in this paper encourages researchers and policy makers alike to take seriously the potential impact of high school interventions on the STEM orientations of female students. Our finding that the intensity of the math and science curriculum reduces the gender gap in science orientation strongly supports this conclusion.

The present study obviously falls short in adequately addressing all the characteristics of high schools that influence the gender gap. Similar to the state of knowledge about teacher quality, our findings suggest that high schools have the potential to shape the orientation towards STEM fields and suggest that the math and science orientation of the school might play an important role, but we still know relatively little about other high school characteristics or programs that achieve this goal. Our own theoretical argument suggests that the ways in which gender identities are constructed plays an important role. Our argument also suggests that commonly held stereotypes are strengthened by the lack of adequate information about science and engineering careers in the local environment, and conversely that the power of these stereotypes over behavior can be reduced through greater exposure to knowledge about science and engineering through the academic curriculum. A third argument was presented recently by Frank et al. (2008), who argue that social dynamics play an important role for the propensity of girls and boys to take math courses. Future research should investigate these issues at greater depth in order to extend our knowledge about the persisting gender gap in STEM degrees. 


\section{Appendix A Samples, Variables, and Missing Data}

The analyses presented in this paper are based on three samples from the National Education Longitudinal Study of 1988 (NELS). NELS is a nationally representative sample of about 25,000 eighth grade students who were first surveyed in the spring of 1988. Subsamples of these students were resurveyed in $1990,1992,1994$, and 2000 so that the students were followed over time as they graduated from high school and entered the labor force or pursued post-secondary degrees. The panel structure of the data combined with the fact that it includes detailed information on educational careers allows us to examine the different questions addressed in this paper. We have briefly described each of the three samples in the main text and provide further details in this appendix. Table A1 also contains a detailed description of the variables used in the different analyses.

NELS 1988-2000 Sample (Pathway Analysis) We restrict the NELS 88-2000 sample to students who participated in the eighth and 12 grade survey (base year and second follow up), the 2000 follow up (fourth follow up). ${ }^{9}$ The size of this restricted sample is 8,320 . From this sample, $1,260(15.2 \%)$ cases are dropped because of missing data on the relevant variables, which brings the analysis sample down to 7,060. All of the analysis use the appropriate weights provided by NELS.

NELS 1988-1992 Sample (High School Context Analysis) We restrict our analysis of the NELS 88-1992 to students who participated in the base year as well as the first and second follow up and to those for which the school filled out a school questionnaire during the first follow up. The size of this sample is $13,640 .{ }^{10} 5,310$ or $38.9 \%$ of these cases have missing data on at least one of the large number of pre-treatment control or other variables. To address this problem, we use multiple imputations based on the multivariate normal model approach with a large number of auxiliary variables such as 10th and 12th grade test scores in reading, math and science.

NELS HSES Sample (High School Context Analysis) The HSES sample used in our analysis contains all 9,740 students who participated in the twelfth grade survey. 1,720 or $17.63 \%$ of the students have missing data on at least one of the variables. Similar to our analysis based on the NELS 1988-1992, we use multiple imputations to recover cases with missing data.

\footnotetext{
${ }^{9}$ This sample restriction excludes high school drop-outs. Although NELS followed students who dropped out of high school, information on intentions to go to college are meaningless so that it makes sense to exclude this group from our analysis.

${ }^{10}$ For the estimation of the curriculum effect we also exclude students who did not change school between eighth and tenth grade and those who changed school between tenth and twelfth grade. Accordingly, the analysis of the curriculum effect is based on students who changed from a middle to a high school and proceeded to 12th grade without dropping out of school or changing the school. This restriction excludes 450 cases.
} 
Table A1: Description of Variables

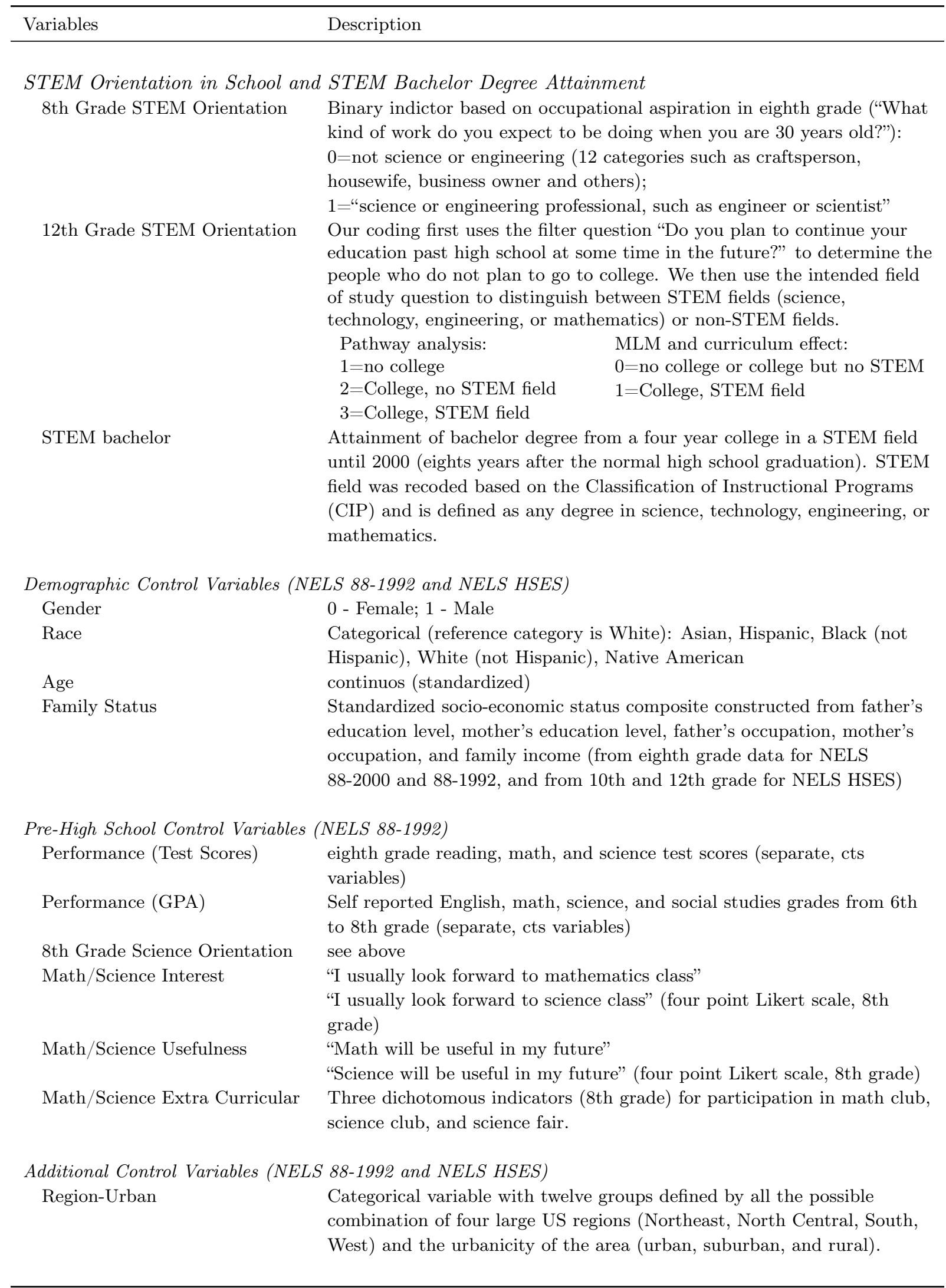

Note: All continuos variables have been standardized for the analysis. 


\section{Appendix B Pathways for Academically Talented Students and Different STEM Subfields}

In this appendix, we present the findings from the pathway analysis for academically talented students, and for different STEM subfields. Academically talented students are defined in terms of their math performance in eighth grade. Restricting the sample to the top $33 \%$ students in terms of math performance leads to similar results but the patterns reported above are even more pronounced (see Table A2). The transition rates during high school play an ever bigger role $(64.1 \%$ compared to $55.3 \%)$ and the different rates of late entry after high school a slightly smaller role $(44.9 \%$ compared to $50.7 \%)$.

The trends presented in Figure 1 suggest that analyzing gender differences in STEM degrees should take into account the substantial differences between sub-fields. Accordingly, we analyze engineering, math and physics as well as bio/life-science respectively and look at how the pathways for these subfields differ from STEM fields in general. Table A2 presents the results of these decompositions. For both engineering as well as math and physics, the results resemble the findings from STEM fields in general. In all three cases, the transition rates in high school play the most important role in explaining gender differences in an engineering BA, while the lower rate of late entry for females after high school plays the second most important role. For biology and life science, the gender gap in bachelor degrees is small and not statistically significant, and therefore a decomposition analysis is not informative.

\section{Appendix C Estimating the Effect of High School Curriculum on the Gender Gap in STEM Orientation}

The literature on the estimation of causal effect using conditioning on observable covariates as an identification strategy has recently focused on matching procedures. Theoretically, estimates based on matched samples provide a number of advantages over regression estimates based on the raw data. Most notably, matching estimates are (quasi) non-parametric, and reduce the need to extrapolate by discarding (or down-weighting) observations without common support in the treatment and control group. A number of recent studies that compare experimental with regression and matching estimates, however, have shown that these theoretical advantages are typically negligible in practice (Cook et al. 2009; Shadish et al. 2008; Angrist and Pischke 2008). These studies instead point at the importance 
Table A2: Decomposition of Gender Gap in STEM BAs, Academically Talented Students and STEM Sub-fields

\begin{tabular}{|c|c|c|c|c|c|}
\hline & & Academical & & & \\
\hline & Personal & Talented & Engin- & Math and & Bio/Life \\
\hline & Orientation & Students & eering & Physics & Sciences \\
\hline Observed Gender Gap in $\%$ & 3.844 & 6.034 & 4.025 & 0.424 & -0.605 \\
\hline ...in M/F Odds Ratio & 1.713 & 1.619 & 3.421 & 1.382 & 0.799 \\
\hline Percent Reduction in Gender Go & if Females ar & Assigned $M$ & Values & & \\
\hline Same 8th Grade Orientation & 10.45 & 14.47 & 4.89 & 22.67 & -23.78 \\
\hline Same 12th Grade Orientation & 68.51 & 78.78 & 71.81 & 92.18 & -70.99 \\
\hline Same HS Transition Rates & 55.31 & 64.08 & 62.24 & 66.45 & -48.37 \\
\hline Same HS Late Entry & 70.8 & 83.96 & 61.2 & -8.88 & -11.05 \\
\hline Same HS Persistence & 5.17 & 4.95 & 6.36 & -0.94 & 7.01 \\
\hline Same Post-HS Transition Rates & 47.1 & 38.16 & 32.26 & 48.43 & 28.56 \\
\hline Same Post-HS Late Entry & 50.66 & 44.85 & 31.96 & 37.91 & -34.36 \\
\hline Same Post-HS Persistence & -3.56 & -6.69 & 0.30 & 10.52 & 62.92 \\
\hline Same Late Entry Rates & 121.46 & 128.8 & 93.16 & 29.04 & -45.41 \\
\hline Same Persistence Rates & 1.31 & -2.12 & 6.79 & 9.48 & 65.45 \\
\hline
\end{tabular}

of the actual set of observed covariates used in the analysis, and the measurement reliability of these constructs. They show that only a comprehensive set of pre-treatment variables that are measured reliably and that are directly related to the selection process (i.e., that go beyond a set of standard demographic measures) can effectively reduce bias from non-random selection into treatment.

In order to estimate the causal effect of the math and science curriculum, we use the fact that the original NELS sample was first interviewed in eighth grade, before these students attended high school. This feature of the data allows us to use a comprehensive set of pre-treatment variables that are directly related to the selection of students into high schools with a strong math and science curriculum. These variables include a comprehensive set of family background variables and other standard demographic measures, plus a set of variables related to the science and engineering orientation in eighth grade such as the occupational aspiration in eighth grade, the extent to which a students looks forwards to their math and science classes, and whether the student thinks that math and science is useful for their future. In addition, we control for eighth grade GPA and test scores in math, science, and reading (for a full list of variables see Table A1). These measures were selected because that they directly relate to the selection of students into high schools with a strong math and science curriculum. The measure of occupational aspirations in eighth grade can also be understood as a 'proxy pretest' variable, which is particularly important for the reduction of bias (Steiner et al. 2010). In addition, the high number of measures connected to the same underlying construct reduces the potential bias introduced by unreliable measurement of the key pre-treatment covariates. For our analysis, we refrain from using 
Figure A1: Balance between Top and Bottom Quartile of Continuos Treatment Variable

(a) Balance in Raw Data

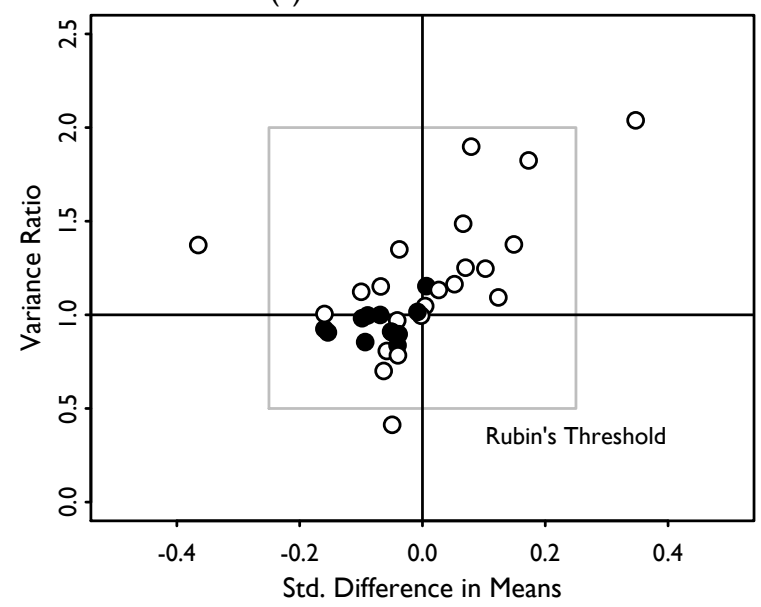

(a) Balance Conditional on Covariates

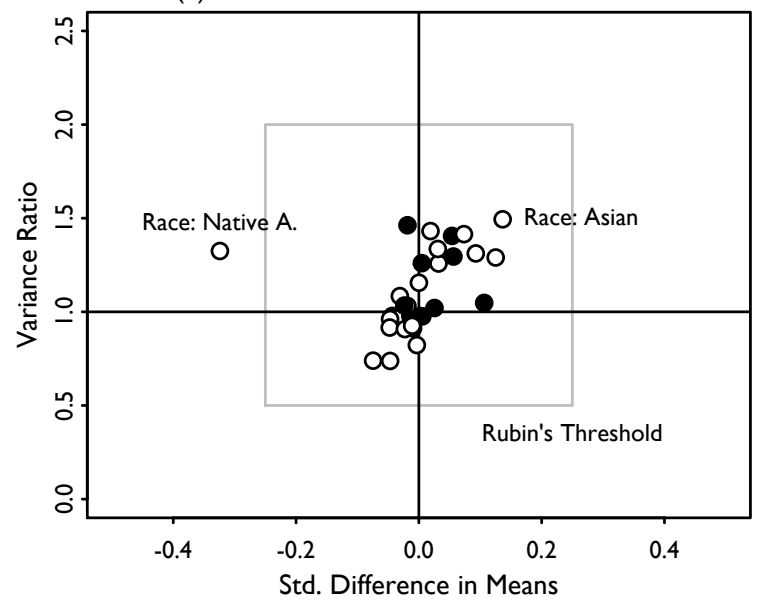

matching procedures because of the common finding that regression and matching based estimates are equally good and because our treatment measure is continuous. Dichotomizing the treatment indicator would be a possibility but we believe that the gains from estimates based on matched samples (if any) are offset by the precision lost introduced through dichotomizing the treatment indicator. To further address this issue, we analyze the balance of the data across different values of the treatment indicator below, and explore alternative model specifications to maximize balance.

The Treatment Indicator Our focal treatment variable is the intensity of the high school course offerings in math and science. We measure this variable based on a set of questions asked in the tenth grade school questionnaire about the courses offered at a school. In particular, we create an index based on the AP or college or university level course offered for 31 different math and science areas such as biology, physics, life science, calculus, and trigonometry, and standardize this index with a mean of zero and a standard devision of one.

Balance between Levels of the Treatment Indicator To examine the balance between different levels of the treatment indicator, we compare the first and fourth quartile of the treatment indicator with respect to forty pre-treatment covariates in the raw data as well as conditional on the control variables. These covariates include the control variables used in the final analysis but also a number of interaction terms between these variables that are not included in the final analysis. Figure A1 shows balance in terms of the standardized difference in means (x-axis) and the variance ratio (y-axis) for the raw data as well as conditional on the covariates in the final analysis. Solid circles indicate key variables such as eighth grade orientation, and math and science performance. These variables 
were selected based on theoretical considerations as well as the size of there effect in the selection and outcome model. The grey rectangle indicates Rubin's (2001) rule of the thumb, which suggests that the absolute standardized differences in means should not be greater than 0.25 and the variance ratio should be between 0.5 and 2. In general, however, imbalance should be reduced without limit. The results show that the covariates clearly increase the balance between the treatment and control group and that the highly relevant variables cluster right around the point of no imbalance. The only variable that falls outside the rectangle is the dummy variable for Native Americans. This group, however, is extremely small with only 30 students in the control group and 20 in the treatment group. Overall, the results indicate that our estimation strategy is effective in reducing the observable imbalance between different levels of the treatment indicator. Alternative specifications did not reduce the imbalance further. 


\section{References}

Adelman, Clifford. 2006. "The Toolbox Revisited. Paths to Degree Completion from High School Through College." Technical report, U.S. Department of Education.

Almquist, E.M., S.S. Angrist, and R. Mickelsen. 1980. "Women's Career Aspirations and Achievements: College and Seven Years After." Work and Occupations 7:367-384.

an Ghaill, Mairtin Mac. 1994. The Making of Men: Masculinities, Sexualities and Schooling. Buckingham: Open University Press.

Andreescu, T., J. A Gallian, J. M Kane, and J. E Mertz. 2008. "Cross-cultural analysis of students with exceptional talent in mathematical problem solving." Notices of the AMS 55:1248-1260.

Angrist, Joshua D and Jorn-Steffen Pischke. 2008. Mostly Harmless Econometrics: An Empiricist's Companion. Princeton University Press.

Angrist, S.S. and E.M. Almquist. 1993. "The Carnegie Mellon Class of 1968: Families, careers, and contingencies." In Women's Lives through Time: Educated American Women of the Twentieth Century, edited by K.D. Hulbert and D.T. Schuster. San Francisco: Jossey-Bass.

Arnold, K.D. 1995. Lives of Promise: What becomes of High School Valedictorians. San Francisco: Jossey-Bass.

Aronson, J. and C. M Steele. 2005. "Stereotypes and the fragility of academic competence, motivation, and self-concept." Handbook of competence and motivation p. 436-456.

Beutel, A.M. and M. Mooney Marini. 1995. "Gender and values." American sociological review 60:436-448.

Buchmann, Claudia and Thomas A. DiPrete. 2006. "The Growing Female Advantage in College Completion: The Role of Family Background and Academic Achievement." American Sociological Review 71:515-541.

Bussey, Kay and Albert Bandura. 1999. "Social cognitive theory of gender development and differentiation." Psychological Review 106:676-713.

Carrell, S. E, M. E Page, and J. E West. 2010. "Sex and Science: How Professor Gender Perpetuates the Gender Gap*." Quarterly Journal of Economics 125:1101-1144. 
Ceci, S. J, W. M Williams, and S. M Barnett. 2009. "Women's underrepresentation in science: Sociocultural and biological considerations." Psychological Bulletin 135:218.

Charles, M. and K. Bradley. 2002. "Equal but separate? A cross-national study of sex segregation in higher education." American Sociological Review 67:573-599.

Coleman, James. 1966. Equality of educational opportunity. U.S. Dept. of Health, Education, and Welfare, Office of Education.

Cook, Thomas D, Peter M. Steiner, and Steffi Pohl. 2009. "How Bias Reduction Is Affected by Covariate Choice, Unreliability, and Mode of Data Analysis: Results From Two Types of WithinStudy Comparisons." Multivariate Behavioral Research 44:828-847.

Correll, S.J. 2001. "Gender and the Career Choice Process: The Role of Biased Self-Assessments 1." American Journal of Sociology 106:1691-1730.

Correll, Shelley J. 2004. "Constraints into Preferences: Gender, Status, and Emerging Career Aspirations." American Sociological Review 69:93-113.

Davies, S. and N. Guppy. 1996. "Fields of Study, College Selectivity, and Student Inequalities in Higher Education." Social Forces 75:1439-1462.

DiPrete, Thomas and Anne McDaniel. 2011. "Family, Gender, and Educational Outcomes in Elementary and Middle School." Paper Presented at the Population Association of America meetings in Washington, D.C.

Duxbury, L.E. and C.A. Higgins. 1991. "Gender differences in work-family conflict." Journal of Applied Psychology 76:60-74.

Eccles, J.S. 2007. "Where are all the women? Gender differences in participation in physical science and engineering." In Why Aren't More Women in Science? Top Researchers Debate the Evidence, edited by S. J. Ceci and W. M. Williams. Washington, D.C.: American Psychological Association.

Eccles, JS and LW Hoffman. 1984. "Sex roles, socialization, and occupational behavior." Child development research and social policy 1:367-420.

Eccles, J. S. 1994. "Understanding women's educational and occupational choices." Psychology of Women Quarterly 18:585-609.

Eisenhart, M. 2008. "We can’t get there from here: High school girls consider engineering." 
Ellison, G. and A. Swanson. 2010. "The Gender Gap in Secondary School Mathematics at High Achievement Levels: Evidence from the American Mathematics Competitions." The Journal of Economic Perspectives 24:109-128.

England, P. 2005. "Gender inequality in labor markets: The role of motherhood and segregation." Social Politics: International Studies in Gender, State 8 Society 12:264.

Felmlee, D.H. 1993. "The Dynamic Interdependence of Women's Employment and Fertility." Social Science Research 22:333-360.

Francis, Becky. 2000. Boys, Girls and Achievement: Addressing the Classroom Issues. Routledge Falmer, 1 edition.

Frank, Kenneth A., Chandra Muller, Kathryn S. Schiller, Catherine Riegle-Crumb, Anna Strassmann Mueller, Robert Crosnoe, and Jennifer Pearson. 2008. "The Social Dynamics of Mathematics Coursetaking in High School." American Journal of Sociology 113:1645-1696.

Gelman, Andrew and Jennifer Hill. 2007. Data Analysis Using Regression and Multilevel/Hierarchical Models. Cambridge: Cambridge University Press.

Gerson, K. 1985. Hard Choices: How Women Decide about Work, Career, and Motherhood. University of California Press.

Good, C., J. Aronson, and J. A Harder. 2008. "Problems in the pipeline: Stereotype threat and women's achievement in high-level math courses." Journal of Applied Developmental Psychology $29: 17-28$.

Guiso, Luigi, Ferdinando Monte, Paola Sapienza, and Luigi Zingales. 2008. "Culture, Gender, and Math." Science 320:1164-1165.

Habashi, M. M, W. G Graziano, D. Evangelou, and I. Ngambeki. 2009. "Teacher Influences on Child Interest in STEM Careers." In Proceedings of the Research in Engineering Education Symposium, Palm Cove, QLD.

Halpern, D. F. 2000. Sex Differences in Cognitive Abilities. Mahwah, NJ: Lawrence Erlbaum Associates.

Hauser, R. M, S. L Tsai, and W. H Sewell. 1983. "A model of stratification with response error in social and psychological variables." Sociology of Education 56:20-46. 
Hedges, LV and A. Nowell. 1995. "Sex differences in mental test scores, variability, and numbers of high-scoring individuals." Science 269:41-45.

Hill, Catherine, Christianne Corbett, and Andresse St. Rose. 2010. Why So Few? Women in Science, Technology, Engineering, and Mathematics. Washington, DC: American Association of University Women.

Hyde, J.S., S.M. Lindberg, Linn M.C., Ellis A.B., and Williams C.C. 2008. "Gender Similarities Characterize Math Performance." Science 321:494-495.

Jacob, B. A, L. Lefgren, and D. P Sims. 2010. "The persistence of teacher-induced learning." Journal of Human Resources 45:915-943.

Jacobs, J. E and M. M Bleeker. 2004. "Girls' and boys' developing interests in math and science: Do parents matter?" New Directions for Child and Adolescent Development 2004:5-21.

Jacobs, J. E, S. Lanza, D. W Osgood, J. S Eccles, and A. Wigfield. 2002. "Changes in children's selfcompetence and values: Gender and domain differences across grades one through twelve." Child Development 73:509-527.

Johnson, M.K. 2001. "Social Orgins, Adolescent Experiences, and Work Value Trajectories during the Transition to Adulthood." Social Forces 80:1307-1340.

Kane, T. J and D. O Staiger. 2008. Estimating teacher impacts on student achievement: An experimental evaluation. National Bureau of Economic Research Cambridge, Mass., USA.

Kimura, D. 2002. "Sex hormones influence human cognitive pattern." Neuroendocrinology Letters 23:67-77.

Konrad, A.M., J. E. Ritchie, P. Lieb, and E. Corrigall. 2000. "Sex differences and similarities in job attribute preferences: A meta-analysis." Psychological bulletin 126:593-641.

Lapan, Richard T., Angela Adams, Sherri Turner, and Jeanne M. Hinkelman. 2000. 'Seventh graders' vocational interest and efficacy expectation patterns." Journal of Career Development 26:215-229.

Lee, J., W. Grigg, and G. Dion. 2007. The nation's report card: Mathematics 200\%. Washington, DC: National Center for Education Statistics, Institute of Education Sciences, US Department of Education.

Legewie, Joscha and Thomas A. DiPrete. 2011. "School Context and the Gender Gap in Educational Achievement." American Sociological Review (forthcoming). 
Liben, L. S, R. S Bigler, and H. R Krogh. 2001. "Pink and Blue Collar Jobs: Children's Judgments of Job Status and Job Aspirations in Relation to Sex of Worker* 1." Journal of Experimental Child Psychology 79:346-363.

Lippa, Richard A. 2005. Gender, Nature, and Nurture. Psychology Press, 2 edition.

Lohman, David F. and Joni M. Lakin. 2009. "Consistencies in sex differences on the cognitive abilities test across countries, grades, test forms, and cohorts." British Journal of Educational Psychology 79:389-407.

Lubinski, D. and C. P Benbow. 1992. "Gender Differences in Abilities and Preferences Among the Gifted: Implications for the Math-Science Pipeline." Current Directions in Psychological Science $1: 61-66$.

Lueptow, L.B., L. Garovich-Szabo, and M.B. Lueptow. 2001. "Social Change and the Persistence of Sex Typing: 1974-1997." Social Forces 80:1-35.

Martin, C. L, D. N Ruble, and J. Szkrybalo. 2002. "Cognitive theories of early gender development." Psychological Bulletin 128:903-933.

Martin, C. L, C. H Wood, and J. K Little. 1990. "The development of gender stereotype components." Child Development 61:1891-1904.

McGee, J. and J. Stockard. 1991. "From a child's view: Children's occupational knowledge and perceptions of occupational characteristics." Sociological studies of child development 4:113-136.

Okamoto, D. and P. England. 1999. "Is There a Supply Side to Occupational Sex Segregation?" Sociological Perspectives 42:557-582.

Owings, Jeffrey. 1998. "High School Curriculum Structure: Effects on Coursetaking and Achievement in Mathematics for High School Graduates." Technical report, US Dept. of Education, Office of Educational Research and Improvement.

Pajares, F. 2005. "Gender Differences in Mathematics Self-Efficacy Beliefs." In Gender differences in mathematics: An integrative psychological approach, edited by A. M Gallagher and J. C Kaufman, pp. 294-315. Cambridge: Cambridge University Press.

Park, Hyunjoon, Jere R Behrman, and Jaesung Choi. 2011. "Causal Effects of Single-Sex Schools on Students' STEM Outcomes by Gender and Parental SES." Unpublished working paper. 
Penner, A.M. 2008. "Gender Differences in Extreme Mathematical Achievement: An International Perspective on Biological and Social Factors 1." American Journal of Sociology 114:138-170.

Plant, E. Ashby, A. L Baylor, C. E Doerr, and R. B Rosenberg-Kima. 2009. "Changing middle-school students' attitudes and performance regarding engineering with computer-based social models." Computers \& Education 53:209-215.

Ridgeway, C. L. 2001. "Gender, status, and leadership." Journal of Social Issues 57:637-655.

Rothstein, J. 2010. "Teacher Quality in Educational Production: Tracking, Decay, and Student Achievement." Quarterly Journal of Economics 125:175-214.

Rubin, Donald B. 2001. "Using Propensity Scores to Help Design Observational Studies: Application to the Tobacco Litigation." Health Services and Outcomes Research Methodology 2:169-188.

Sewell, W. H, A. O Haller, and A. Portes. 1969. "The educational and early occupational attainment process." American Sociological Review 34:82-92.

Sewell, W. H and R. M Hauser. 1975. Education, Occupation, and Earnings. Achievement in the Early Career. New York: Academic Press.

Seymour, E. and N.M Hewitt. 1997. Talking About Leaving: Why Undergraduates Leave the Sciences. Boulder, CO: Westview Press.

Shadish, William R., M. H. Clark, and Peter M. Steiner. 2008. "Can Nonrandomized Experiments Yield Accurate Answers? A Randomized Experiment Comparing Random and Nonrandom Assignments." Journal of the American Statistical Association 103:1334-1344.

Shauman, K.A. 2008. "Are There Sex Differences in the Utilization of Educational Capital Among College-Educated Workers?" Unpublished working paper.

Signorella, M. L, R. S Bigler, and L. S Liben. 1993. "Developmental differences in children's gender schemata about others: A meta-analytic review." Developmental Review 13:147-183.

Steiner, Peter M., Thomas D. Cook, William R. Shadish, and M. H. Clark. 2010. "The importance of covariate selection in controlling for selection bias in observational studies." Psychological Methods 15:250-267. PMID: 20822251.

Turner, S. L and R. T Lapan. 2005. "Evaluation of an intervention to increase non-traditional career interests and career-related self-efficacy among middle-school adolescents." Journal of Vocational Behavior 66:516-531. 
Weinberger, Catherine J. 2005. "Is the science and engineering workforce drawn from the far upper tail of the math ability distribution."

West, C. and D. H Zimmerman. 1987. "Doing gender." Gender \& society 1:125.

Williams, J. 2000. Unbending Gender: Why Family and Work Conflict and What to Do About It. Oxford: Oxford University Press.

Wilson, K.L. and J.P. Boldizar. 1990. "Gender Segregation in Higher Education: Effects of Aspirations, Mathematics Achievement, and Income." Sociology of Education 63:62-74.

Xie, Y. and K. A Shauman. 1997. "Modeling the sex-typing of occupational choice." Sociological methods \& research 26:233.

Xie, Yu and Kimberlee A. Shauman. 2005. Women in Science: Career Processes and Outcomes. Cambridge, MA: Harvard University Press.

Yeager, D. S and G. M Walton. 2011. "Social-Psychological Interventions in Education: They're Not Magic." Review of Educational Research . 